\title{
REFLEXÕES SOBRE A IMPORTÂNCIA DOS ESTUDOS DE EDUCAÇÃO COMPARADA NA ATUALIDADE ${ }^{1}$
}

\author{
Elma Júlia Gonçalves Carvalho ${ }^{2}$
}

\section{RESUMO}

A metodologia comparada é um rico instrumento analítico dos sistemas educativos. Auxiliando a identificar semelhanças e diferenças, amplia o campo de análise e de compreensão da realidade nacional em face da de outros países, particularmente no campo das políticas públicas e gestão da educação. No entanto, esse recurso é pouco explorado no Brasil. É propósito, neste texto, discutir as razões pelas quais os estudos comparados se configuram como uma área de estudos de progressiva importância no contexto da globalização e, pontuando os rumos da educação comparada como área do conhecimento, destacar sua relevância para a compreensão do que vem acontecendo no campo da educação na atualidade. Palavras-chave: estudos comparados, educação, políticas públicas.

\section{REFLECTIONS ON THE IMPORTANCE OF STUDIES COMPARATIVE EDUCATION TODAY}

\begin{abstract}
Comparative methodology is an extremely rich analytic tool for educational systems. Since it identifies similar and different issues, it broadens the field of analysis and understanding on national reality when contrasted to that of other countries. This is especially true in public policies and administration of education, although such resource is only slightly developed in Brazil. Current research discusses why comparative studies are an area of progressive importance with the context of globalization. Highlighting comparative education as a field of knowledge, the text insists on its relevance for the comprehension of what occurs in the contemporary educational field.
\end{abstract}

Keywords: comparative studies; education; public policies.

\section{Introdução}

O presente texto é resultado da pesquisa "Política de Autonomia da Gestão Escolar: uma análise comparada entre Brasil e Portugal", na qual analisamos as reformas educativas brasileira e portuguesa realizadas na década de 1990 no campo da administração da educação básica. Em decorrência da metodologia e dos procedimentos adotados na pesquisa, foi necessário aprofundar conhecimentos sobre a pesquisa comparada, sua metodologia, seus fundamentos teóricos, as tendências e os temas das investigações que vêm sendo realizadas. Nesse percurso, pudemos observar a importância da Educação Comparada para as reflexões atuais sobre a educação. 
Tal importância já se manifesta nos primórdios de organização dessa área do conhecimento, os quais coincidem com o momento de criação dos primeiros sistemas públicos de educação nacional. Por meio de estudos comparativos, obtinham-se informações sobre a dinâmica dos sistemas educacionais bem como de soluções encontradas em outros contextos nacionais, de formar a apoiar os governos dos diferentes países na organização da educação e na solução de problemas de ordem tanto pedagógica quanto administrativa. (MADEIRA, 2008).

Durante o século XX, a Educação Comparada alcançou grande prestígio e, ampliando progressivamente seu campo de investigação e de ação, assumiu uma dimensão internacional, especialmente devido aos trabalhos desenvolvidos pelos organismos internacionais (UNESCO, Banco Mundial, OCDE, dentre outros) e pela comunidade científica internacional.

Porém, a partir da década de 1970, após vivenciar esse período de expansão e de valorização, essa forma de estudos entrou em declínio, por diversas razões, dentre as quais podemos citar a própria descrença na educação, que deixou de ser vista como um fator de progresso, de crescimento econômico e de modernização.

Nos últimos anos, especialmente a partir de 1990, o interesse pela comparação vem se reativando e promovendo uma renovação e uma ampliação das abordagens comparadas no campo da educação. Sentidos alternativos vêm sendo dados para o trabalho comparativo, mostrando sua potencialidade.

Com a finalidade de contribuir para o debate, utilizamos os resultados da pesquisa mencionada e organizamos algumas informações sobre o campo da Educação Comparada. Inicialmente, em linhas gerais, apresentamos os caminhos percorridos pela investigação no campo da Educação Comparada, especialmente em seus aspectos teóricos e metodológicos, para, em seguida, desenvolvermos nossa argumentação a respeito da importância da educação comparada na atualidade.

\section{O estudo comparativo na educação}

Os estudos de Educação Comparada são relativamente recentes. As obras que poderiam ser consideradas de caráter científico surgem no final do século XIX, embora, em 1817, em seu "Esquisse et vus preliminaries d'um ouvrage sur education comparée et séries de questions sur l'education", Marc-Antonie Jullien já tenha esboçado os métodos e as tarefas desse novo campo (GOERGEN, 1991). Esse surgimento tardio relaciona-se ao fato de que, tendo como objeto o sistema de ensino de cada país, esse campo de estudos não poderia existir sem que os sistemas educacionais nacionais se organizassem e consolidassem (LOURENÇO FILHO, 2004).

As primeiras pesquisas destinavam-se a comparar os sistemas nacionais de ensino (especialmente europeus), fornecendo informações para que os diferentes países pudessem copiar uns dos outros o que existia de bom e, ao mesmo tempo, evitar os erros. Assim, ao longo do século XIX, em diversos países do mundo, inclusive Argentina Chile e Brasil, alguns educadores (políticos ou representantes de governo) foram encarregados de empreender viagens e observar as formas de educação em outros países ${ }^{3}$.

No decorrer do século XX, foi ocorrendo a sistematização desse novo campo de estudo. Com objeto, finalidades e campos de ação definidos e procedimentos e métodos de investigação mais seguros e objetivos, a Educação Comparada adquiriu status de ciência. Ao mesmo tempo, realizaram-se pesquisas de caráter regional, nacional e internacional, 
organizaram-se congressos, conferências ou colóquios e, com temas variados, publicaram-se numerosas obras, especialmente, revistas, anuários, bibliografias e monografias. Difundiramse, assim, dados e informações sobre os sistemas educativos dos diferentes países. A maioria das pesquisas era de caráter quantitativo (tabelas estatísticas e avaliações padronizadas) e seus resultados foram utilizados como orientação para a tomada de decisões políticas e para as reformas dos sistemas educativos (BONITATIBUS, 1989).

Observamos que, apesar das distintas perspectivas teórico-metodológicas assumidas pela Educação Comparada nos diferentes momentos, alguns aspectos comuns foram mantidos em seus procedimentos: 1) os Estados-nação como referência da análise dos sistemas educativos ${ }^{4}$; 2) a ideologia do progresso; 3) a crença na ciência e no conhecimento objetivo para a compreensão dos fenômenos; 4) a concepção de que o funcionamento dos sistemas educativos deve se basear em princípios comuns e universais.

Nesse período, fornecendo aos governos informações que orientavam a tomada de decisões políticas e contribuindo para a melhoria dos sistemas de ensino, o trabalho comparativo desempenhou papel importante na organização dos sistemas educativos nacionais, especialmente quanto à solução e à prevenção de problemas de ordem pedagógica e administrativa ${ }^{5}$. Kandel, nos anos de 1950, já enfatizava a importância do estudo comparado para a formulação de políticas educativas. Segundo ele, "a obrigação dos historiadores da pedagogia e dos que se dedicam à Pedagogia Comparada é facilitar as tarefas do homem de Estado com os frutos de sua investigação [...] Por conseguinte, nossa ciência pode e deve auxiliar a política" (KANDEL, 1955 apud MOLLIS, 1990, p. 316).

Entretanto, entre as décadas de 1970 e 1980, a educação comparada sofreu uma perda progressiva de prestígio, em decorrência das intensas críticas às interpretações das denominadas "Teorias da Modernização Social", "Teoria do Capital Humano" e "Teorias Desenvolvimentistas", marcadas pela convicção de que a educação teria um papel primordial no processo de mudança social, bem como dos próprios resultados alcançados por elas. Também a "Teoria da Dependência" e a "Teoria da Reprodução" passaram a ser alvo de críticas, especialmente por considerarem a educação apenas como instrumento de dominação e de reprodução da ideologia das classes dominantes, sem oferecer alternativas viáveis (BONITATIBUS, 1989).

Nesse contexto, seus procedimentos de investigação, sua validade científica, suas bases teóricas e mesmo suas finalidades foram questionados.

Parte desses questionamentos dizem respeito ao fato de que seus resultados eram largamente utilizados para legitimar ações reformadoras em nível nacional, cujas orientações ou diretrizes eram fornecidas por organismos internacionais (ONU, UNESCO, FMI, Banco Mundial, OCDE),

Outros apontam o descrédito quanto aos seus resultados, explicando-o por suas limitações metodológicas e pela natureza acadêmica assumida pela Educação Comparada, como revela Halls (1971):

A crise de identidade dos comparatistas acentuou-se nos últimos cinco anos na medida em que foram excluídos do processo de reforma dos sistemas educacionais. Ao contrário dos psicólogos, dos sociólogos e ultimamente até dos filósofos, eles não encontraram seu lugar a partir do qual possam influenciar a realidade educacional [...] As teorias e constructos da Educação Comparada - este campo de pesquisa que, entrementes, tem mais de um 
século de vida - não souberam, principalmente nos últimos tempos, demonstrar seu valor para as tarefas práticas, com as quais se ocupam os reformadores dos sistemas educacionais, não importando se seu ponto de partida era o princípio dos "fatores" ou das "forças propulsoras" ou se procediam de maneira "indutiva", "quantitativa" ou através da "solução de problemas" ou ainda com fundamento em outras ciências sociais. Por isso temos que perguntar novamente: têm os estudos comparados alguma utilidade ou são apenas exercícios estimulantes bastante exóticos e sem nenhum sentido? Se o comparatista em educação, em conseqüência do seu desespero, se refugia no puramente acadêmico, certamente será o único dentre todos os representantes de todos os setores da educação a agir assim; hoje até o historiador da educação - e com razão! - sente-se obrigado a contribuir para a construção do sistema educacional (HALLS, 1971 apud GOERGEN, 1991, p. 14).

Segundo Goergen (1991) não podemos julgar uma atividade intelectual apenas por seu maior ou menor grau de intervenção na realidade. Entretanto, não podemos deixar de considerar as afirmações de Halls, pois elas apontam algumas das dificuldades enfrentadas pela Educação Comparada, bem como as críticas que lhe são endereçadas.

Kelly e Altbach (1990) e Altbach (1990) relatam que, nesse período, nos Estados Unidos, a Educação Comparada, especialmente a institucional, foi afetada pelo desaparecimento, quase completo, dos financiamentos externos destinados aos departamentos de educação. As fundações privadas perderam o interesse pela educação, reduzindo ou suspendendo o apoio a muitos programas e centros de formação e investigação. Assim, os comparatistas, em sua maioria, acabaram ficando abandonados aos seus próprios meios, o que repercutiu na redução do número de pesquisas e publicações.

No Brasil, observamos a escassez da produção científica e a exclusão progressiva da disciplina Educação Comparada dos cursos de graduação e de pós-graduação em educação ${ }^{6}$. Autores como Goergen (1991), Nogueira (1994) e Martini (1996) atribuem esse declínio a fatores diversos e interligados, tais como: dificuldade de acesso a bibliografias especializadas e atualizadas; dificuldade para a realização de viagens de intercâmbios; ausência de bancos de dados atualizados; pouco domínio de línguas estrangeiras, o que resulta em uma inexpressiva bibliografia traduzida; falta de professores qualificados na área; escassez de grupos de pesquisas voltados para o aprofundamento do conhecimento e para a fundamentação das investigações; escassez de cursos de pós-graduação voltados para a formação de professores para a área; falta de clareza quanto ao papel dessa área nos cursos de formação de professores, em particular nos de Pedagogia; falta de aprofundamento do estudo do "pedagógico" e ausência de debates em torno do tema; escassez de material para estudo; por fim, a desvinculação entre ensino e pesquisa.

$\mathrm{O}$ mesmo pode ser afirmado quanto à América Latina como um todo. Segundo Lamarra; Mollis e Rubio (2005, p. 180):

[...] Educação Comparada tem um limitado desenvolvimento acadêmico na América Latina. O desenvolvimento limitado deste campo é diretamente proporcional à escassa base acadêmica ou racional para a investigação comparativa, aplicadas à educação de decisão política. 
Entre as consequências apontadas pelos autores, destacamos:

A ausência de pensamento sistemático, refletivo, comparativo, tem caracterizado a implementação de inúmeros dispositivos de políticas educacionais que resultaram em fracasso sem precedentes na história dos sistemas de educação pública americana. A adoção de "prescrições educacionais internacionais" que apoiavam as reformas na região e as dos países pós-socialistas, foi realizada à margem da contribuição da pesquisa comparativa regional.

Nos últimos anos, no entanto, especialmente no meio acadêmico ${ }^{7}$, ocorreu no Brasil um movimento de resgate desse campo de estudos. Observa-se o aumento progressivo das publicações científicas nacionais (WERLE e CASTRO, 2000), particularmente com o tema das políticas e da gestão da educação. A realização de encontros e congressos também favoreceu o intercâmbio entre pesquisadores e ampliou as possibilidades de desenvolvimento de projetos comuns de investigação (SAVIANI, 2001).

Essa revitalização dos estudos comparativos não é uma particularidade do Brasil: tem ocorrido em diversos países, tornando-se um processo internacional. A partir da década de 1990, com a reorganização da ordem mundial e dos processos de globalização, da desnacionalização da economia, do enfraquecimento do Estado-nação e da forte influência das agências internacionais sobre as políticas nacionais de educação, houve um crescente interesse pela realidade educacional de outros países. Dessa maneira, ocorreu um processo de revalorização da educação comparada em nível internacional.

Entre os fatores que favoreceram essa revalorização, Ferran Ferrer (2002, p. 45-46) arrola os seguintes:

- A internacionalização dos fenômenos sociais, econômicos e políticos, em geral, e da educação, em particular.

- As mudanças no ordenamento político mundial, a exemplo da criação do espaço político da União Europeia e de iniciativas embrionárias similares na América Latina.

- A crescente importância dos movimentos migratórios entre países, o que implica mudar ou adaptar o background educativo da população (preparando em e para um contexto cultural concreto através de seu sistema educativo) e um contexto cultural diferente.

- A consciência de que, na nova sociedade do conhecimento, o mundo está cada vez mais dividido em dois ou três grupos de países, não só no âmbito econômico, mas também no educativo. Acredita-se que, precisamente porque as desigualdades não são só econômicas, a educação pode contribuir para a melhoria dos países e para sua adaptação a esse novo tipo de sociedade.

- A crescente importância midiática de certos organismos internacionais que atuam no âmbito da educação. A Educação Comparada trabalha em relação estreita com os mesmos.

- O aumento da compreensão internacional e uma maior consciência da necessidade de uma educação para a paz. Este, de fato, é um dos objetivos clássicos da Educação Comparada. 
Tal revalorização, acompanhada de críticas aos modos de interpretação e quadros de análise anteriores, abre novas perspectivas teórico-metodológicas. Conforme Kelly e Altbach (1990, p. 354),

Desde 1977 têm surgido quatro tipos de desafios para as tradições de investigações estabelecidas na educação comparada. São as seguintes: 1) os que questionam a ideia de nação-estado ou as características nacionais que constituem o parâmetro principal de definição do estudo comparado; 2) os que questionam o uso de modelo de insumos-produto e o exemplo exclusivo de quantificação; 3) os que põem em dúvida o papel do funcionamento estrutural como premissa teórica que sustenta o estudo dos fenômenos investigados; 4) os que dirigem a atenção a novos temas de investigação.

Segundo Beech (2007, p. 1), "o mundo em que vivemos está mudando - tendo em conta que uma das funções fundamentais da educação comparada é compreender o mundo - as teorias, técnicas e estratégias utilizadas na educação comparada devem ser repensadas". O item seguinte deste artigo é destinado a uma reflexão sobre esses desafios ou orientações.

\section{Os novos horizontes da Educação Comparada}

Segundo Malet (2004, p.1301), os novos desafios enfrentados pela Educação Comparada relacionam-se a alguns fatores: "o crescimento de problemáticas educativas transculturais, o enfraquecimento dos Estados-nação que acompanhou o crescimento dos territórios identitários supranacionais (como a Europa) ou intranacionais, como as regras, e fenômenos de expansão e interdependência cultural (globalização)". O enfrentamento de tais desafios explica, em grande parte, a renovação do interesse pela comparação e a adoção de novas perspectivas de investigação na área.

Para Kelly e Altbach (1990), quando as revistas Comparative Education e Comparative Education Review publicaram estudos sobre o "estado da arte", mostraram que, a partir de 1977, mudanças significativas têm ocorrido nesse campo de estudo. Nos inúmeros artigos produzidos desde então, os autores têm questionado a adoção do Estado-nação como unidade de comparação e marco de referência nas investigações sobre as relações entre escola e sociedade, ou seja, têm desvalorizado a categoria de análise principal da educação comparada. Suscitando intensos debates, tais publicações têm aberto espaço para a adoção de diferentes perspectivas e unidades de análise, bem como para a diversificação dos princípios e métodos de investigação.

Da variedade de posicionamentos quanto aos rumos a ser tomados nesse campo de estudos, destacamos dois que nos parecem relevantes.

O primeiro é que, de uma perspectiva global, os autores analisam a educação como um fenômeno que ultrapassa o nível nacional. No entanto, eles divergem quanto à dimensão e ao alcance dos processos de globalização.

Para alguns, as mudanças na economia capitalista mundial são a força diretora da globalização. Operando transnacionalmente, essa força rompe ou ultrapassa as fronteiras nacionais e, ao mesmo tempo, enfraquece o poder dos Estados-nação. Segundo Madeira (2008, p. 7), "tais autores, a exemplo de Usher e Edwuards (1994), argumentam que o papel subalterno do Estado na definição dos objetivos educacionais afecta a transmissão de ideias nacionais tornando inviável a criação de uma cultura nacional”. 
Outros, com uma abordagem designada de "Cultura Educacional Mundial Comum" (Meyer, Boli e Thomas), entendem que os Estados são "moldados a um nível supranacional através da ideologia do mundo dominante (ou Ocidente) e não como criações nacionais autônomas e únicas" (DALE, 2004, p. 426). Esses autores argumentam:

[...] Diferenças entre as várias realizações particulares resultam da organização dessa realização a partir da ênfase variável ou das interpretações de regras institucionais mais gerais [...]. Não se deve ver estas instituições em toda a sua diversidade apenas como construções da experiência humana em contextos locais, mas como algo que se desenvolve a partir de uma cultura histórica universalística dominante [...]. Assim, nos sistemas sociais modernos, é profícuo ver a estrutura social não como a reunião de padrões de interacção local, mas como edifícios ideológicos de elementos institucionalizados que substanciam a sua autoridade em regras e concepções mais universais. As estruturas formais da sociedade, desde a definição e propriedades do individual até à forma e ao conteúdo de organizações como as escolas, as empresas, os movimentos sociais e os estados, derivam ou são ajustadas para se adequarem às regras muito gerais que possuem pelo mundo fora significado e poder (MEYER et al., 1997, p. 27-29 apud DALE, 2004, p. 428 , grifos no original).

Nesta abordagem, a educação é considerada um fenômeno mundial, cujas características não se definem no plano dos Estados- nação, ou seja,

longe de serem autonomamente construídas a um nível nacional, as políticas nacionais são em essência pouco mais do que interpretações de versões ou guiões que são informados por, e recebem a sua legitimação de, ideologias, valores e culturas de nível mundial (DALE, 2004, p. 429).

Meyer e Ramirez (2002, p. 97-98), entendendo que o desenvolvimento dos sistemas educativos nacionais e as categorias curriculares se explicam através de modelos universais de educação, de Estado e de sociedade, apontam cinco indicadores de que existe um processo de homogeneização mundial da educação produzido pela globalização:

1) A origem de modelos racionalizados de Estados-nação e de educação de massas e de elite nos séculos XIX e XX produziu instituições mais homogêneas nos diferentes países do que se havia podido prever tendo em conta a variedade real das sociedades e culturas nacionais.

2) Com o transcurso do tempo, os modelos mundiais exerceram uma crescente força sobre os sistemas educativos nacionais, produzindo uma crescente difusão e uniformização.

3) Os modelos educativos se difundem cada vez mais a partir dos organismos internacionais e das ciências e profissões educativas; os modelos educativos se difundem cada vez menos diretamente das principais nações para as periféricas.

4) Com o transcurso do tempo, diminui o impacto das características políticas, sociais e econômicas nacionais endógenas sobre os sistemas econômicos nacionais. 
5) Os fatores que afetam a mudança educativa nacional estão cada vez mais relacionados com a extensão e o caráter dos vínculos nacionais com a sociedade mundial. Quanto mais se vê imerso um Estado-nação na sociedade mundial e vinculado com suas organizações de transmissão, tanto mais se corresponderá o sistema educativo com os modelos mundiais e mudará de direção para adaptar-se às mudanças que ocorrerem no âmbito mundial.

Outros, ainda, a exemplo de Roger Dale, consideram que os processos de globalização são mais importantes que nunca para a compreensão da política e da prática educacionais, especialmente por se tratar de um momento de mudanças nas relações entre os Estados e as forças supranacionais. Ao interrogar como e até que ponto essas mudanças afetam a educação (DALE, 2002), o autor identifica a construção de uma "agenda globalmente estruturada para a educação". Segundo ele, as agendas nacionais para a educação, que até recentemente eram determinadas por fatos de nível nacional, paulatinamente passam a acompanhar as agendas definidas pela economia e pela política globais. Ou seja,

De uma forma muito crítica, neste contexto, todos os quadros regulatórios nacionais são agora, em maior ou menor medida, moldados e delimitados por forças supranacionais, assim como por forças político-econômicas nacionais. E é por estas vias indirectas, através da influência sobre o estado e sobre o modo de regulação, que a globalização tem os seus mais óbvios e importantes efeitos sobre os sistemas educativos nacionais (DALE, 2004, p. 441).

Para demonstrar que a globalização afeta os sistemas educativos nacionais, Dale (2004, p. 436) utiliza os argumentos de que "a globalização é um conjunto de dispositivos políticoeconômicos para a organização da economia global, conduzido pela necessidade de manter o sistema capitalista" e de que "a adesão aos seus princípios é veiculada através da pressão econômica e da percepção do interesse nacional próprio". Ele a concebe como um processo "complexo e frequentemente contraditório que se centra em torno dos três principais agrupamentos de estados, 'Europa', 'América' e 'Ásia"', os quais "possuem diferentes níveis de interação e integração e podem até certo ponto ser vistas como competindo entre si [...] Contudo, os agrupamentos regionais partilham a preocupação com o controlo e concordam sobre certas regras do jogo [...]" (DALE, 2004, p. 136-137).

Ele pondera, entretanto, que, apesar da influência homogeneizadora da globalização, seus efeitos afetam de maneira diferente os sistemas de educação, ou seja, não determinam totalmente sua forma e o seu funcionamento, já que os diferentes países têm respondido com estratégias distintas a similares problemas. De acordo com suas palavras:

[...] a globalização representa, em efeito, uma mudança de paradigmas, porém, não se supõe por ela que o sistema mundial esteja menos "baseado no Estado" ou que os sistemas de educação venham a se desengajar do Estado. A globalização tampouco conduz necessariamente à homogeneização ou inclusive ao aumento de semelhança entre os sistemas educacionais estatais (DALE, 2002, p. 87)

Esse posicionamento é compartilhado por outros autores. Segundo Madeira (2008, p. 7), alguns argumentam que a globalização ou internacionalização "afeta de forma marginal os sistemas educativos registrando apenas uma 'internacionalização parcial' da educação, "a exemplo de Andy Green $(1997 ; 1999)$ e Hirst \& Thompson (1996)". 
O reconhecimento de que os efeitos da globalização variam de lugar para lugar faz com que outros autores chamem a atenção para a natureza e as implicações de tais efeitos em nível nacional ${ }^{8}$. Esses estudos apontam para o contraste entre a "difusão global dos modelos educacionais transnacionalmente padronizados e a persistência das diversas redes de interrelacionamento sócio cultural", o que tem resultado não em uma conversão crescente, mas em uma diferenciação dos sistemas (SCHRIEWER, 1995, p. 269). Em outros termos, eles destacam "a natureza não linear e contingente dos processos de globalização e do impacto repetidamente provocado nesses processos por potenciais geradores de desvios" (SCHRIEWER, 1995, p. 272), abrindo espaço no campo da educação comparada para o estudo de configurações histórico-culturais particulares.

O segundo posicionamento quanto aos rumos a ser tomados pela Educação Comparada é o da perspectiva local. Em contraposição ao etnocentrismo e à universalização ou homogeneização da interpretação das ações educativas ou de funcionamento das instituições, a tendência dos autores que assumem essa perspectiva é estudar as configurações históricoculturais regionais e as especificidades locais (CROSSLEY, 2002 ${ }^{9}$ ).

Nesse caso, os comparatistas, considerando que os processos de globalização suscitam, no nível local e regional, distintas respostas, oposições e apropriações culturais, propõem que as análises tenham como ponto de partida a realidade local, que focalizem a racionalidade dos atores educativos, a centralidade do discurso na construção desses fenômenos, a diversidade étnica e cultural. Essa seria a forma de se resgatar a heterogeneidade, a singularidade de cada cultura e as individualidades e, assim, encontrar alternativas para as práticas educativas. Segundo Gonçalvez e Silva (2000, p. 29),

Tendo, como campo, as relações entabuladas entre pessoas e grupos, no cotidiano da vida em sociedade, os estudos comparados sensíveis à diversidade de visões de mundo, de experiências vividas, que se cruzam e entrecruzam, propõem-se: análise de realidades na perspectiva do que as vivem; divulgação de visões de mundo particulares, de pensamentos próprios a grupos étnicos e sociais; reunião de elementos para intercâmbio de "referências capazes de transformação" (Nkomo, 1990) de sociedades humanamente injustas; organização e manutenção de redes constituídas de pontos de ligação locais e regionais, de linhas de relações históricas, sociais e culturais (Santos, 1996) que ponham em conexão diferentes pensamentos, de valores que vêm permitindo aos diferentes grupos sociais recriarem-se, sem perda de suas raízes, no convívio com os outros.

Nesta abordagem, o outro é posto em discussão, isto é, as minorias e os grupos que têm outras formas de vida e de cultura. A preocupação dos estudiosos comparatistas consiste em esclarecer os processos de apropriação dos fenômenos educativos pelos próprios atores, o que, segundo Malet (2004, p. 1313), "significa o deslocamento progressivo do interesse de conhecimento do comparatismo dos fatos para os processos educativos, e uma atenção mais forte para o sentido dos fenômenos educativos". A este propósito, Nóvoa sublinha:

[...] o Outro é a razão de ser da Educação Comparada. O Outro é o que serve de modelo ou de referência, que legitima acções ou que impõe silêncios que se imita ou que se coloniza. A Educação Comparada faz parte de um campo de poderes no seio do qual se constroem os centros e as periferias, se 
constroem as práticas discursivas que consagram os sentidos e definem os limites. As práticas comparativas ajudam a difundir, a nível mundial, um modelo de escola que se desenvolveu na Europa, mas que se tornou universal: a força deste modelo mede-se pela sua capacidade de ser olhado não como o melhor sistema, mas o único possível ou mesmo imaginável (NÓVOA, 1998, p. 51-52).

Em síntese, a educação comparada é assim concebida, segundo Nóvoa (1994, p. 105), como resultado de um movimento duplo. De um lado, é marcada "por uma presença crescente das questões educativas na criação de identidades escolares, definidas não tanto numa perspectiva geográfica, mas no sentido de uma pertença a certas comunidades discursivas". De outro, caracteriza-se por "uma reorganização dos espaços educativos, através das regulações econômicas e políticas que atravessam as fronteiras dos diferentes países".

Em tal situação, segundo Nóvoa (1994, p. 105), o conceito de comparação adquire novas conotações, "deslocando-se da referência tradicional inter-países para dimensões simultaneamente intra e extra nacionais, isto é, centradas nas comunidades de referência dos actores locais e nos processos de regulação ao nível internacional”.

De acordo com Malet (2004, p. 1311), esses estudos desenvolveram-se como uma reação contra:

a) as condições objetivas e fechadas dos fenômenos educativos e culturais que o funcionalismo tende a promover;

b) as perspectivas de evolucionismo social que, cegadas por uma concepção continuísta da história e uma abordagem pragmática dos fatos educativos, tende a descuidar dos processos de mudanças social;

c) o consensualismo, que impede a empreitada científica de questionar seus fins, o que constitui o melhor meio de eludi-los, sobretudo quando os espaços de intervenção ultrapassam as fronteiras nacionais.

Ao mesmo tempo, ele observa que o afastamento progressivo dos postulados e dos quadros de análise tradicionais dos processos educativos, ou seja, das preocupações cientificistas, pragmáticas ou reformadoras (MALET, 2004) que tomam o Estado-nação como unidade de análise, corresponde a um (re)enquadramento da leitura dos fenômenos educativos: a perspectiva é a das diferenças pessoais, regionais e culturais, com base na cultura e no discurso.

A esse respeito Altbach e Kelly (1990, p. 13) comentam:

As críticas dos anos setenta deram origem a uma literatura que começou a considerar quem tinha freqüentado a escola, assim como a desigualdade de oportunidades, experiência e resultado de mulheres, minorias étnicas, raciais e estratos sociais. Neste tipo de comparação os autores não enfocavam em seu trabalho a comparação entre países, mas se dedicavam sobretudo a comparar a experiência escolar de mulheres, minorias e estratos sociais.

A preocupação diante da resistência das desigualdades sociais, por uma parte, e, por outra, o reconhecimento de que as contribuições educativas realizadas em micronível não garantiram a solução dos problemas da educação nem o desenvolvimento sócio-econômico, induziram os investigadores a estudar 
mais a fundo o que se ensinava nas escolas e o modo em que a qualidade e os conteúdos da educação influíam no seu uso por parte das distintas categorias de alunos. Na década atual se tem começado a relacionar os processos de ensino com ampla variedade de resultados educativos, pessoais e sociais, o que tem propiciado o desenho de estratégias inovadoras de investigação.

Assim, no atual contexto, criaram-se condições não apenas para o surgimento de novas categorias de análise dos sistemas educativos como também para indagações sobre a importância da educação comparada na solução dos problemas atuais.

\section{A importância do estudo comparativo para o estabelecimento de políticas públicas e para a gestão da educação}

No que diz respeito às políticas públicas da gestão em educação ${ }^{10}$, não se pode desprezar a validade metodológica e instrumental dos estudos comparativos, especialmente quando se considera que existe um processo econômico-financeiro de "globalização", com desdobramentos políticos, culturais e educacionais. São indicativas desse processo a internacionalização de fóruns de consulta e de decisões políticas e a influência crescente das agências internacionais (OCDE, UNESCO, FMI, Banco Mundial e etc.) na elaboração das políticas internas dos "países de periferia". Lideradas pelos "países centrais", por meio de programas de cooperação, essas agências prescrevem o modo como os países devem operar as reformas $^{11}$ (BARROSO 2003, BARROSO e VISEU, 2003), desempenhando, assim, um papel decisivo na normatização e padronização das estruturas organizacionais e das políticas educativas.

Segundo Furter (1982, p. 46-47), na nova situação mundial, em razão do caráter transnacional do capital, os centros de decisão se deslocam para fora do alcance nacional, inclusive no que diz respeito ao sistema educacional. Ele caracteriza alguns aspectos em que essa mundialização se manifesta: 1) os efeitos universalizantes da difusão da tecnologia moderna $^{12}$, já que esta implica a unificação das clientelas e dos mercados de formação; 2) a difusão unilateral dos modelos de qualidade, das normas científicas e dos critérios norteamericanos; 3) a organização de empresas e de programas como as escolas internacionais ou o bacharelado internacional; 4) os efeitos da assistência técnica internacional, com suas migrações maciças de especialistas e de estagiários, na manutenção e no reforço de um sistema mundial único de escolarização.

Além disso, alguns estudos de caráter comparativo têm demonstrado que países diferentes, ocupando lugares distintos no sistema mundial, estão percorrendo caminhos bastante semelhantes no desenvolvimento das políticas públicas em educação.

Parece-nos interessante considerar as palavras de Bernestein (1990, p. 139): "os sistemas educativos modernos são no essencial muito mais similares do que distintos, quaisquer que sejam as diferenças e práticas políticas que separam as sociedades modernas". É interessante também atentar para as afirmações de Lima e Afonso (2002, p. 7): "não obstante os distintos condicionamentos políticos, culturais e econômicos de cada Estado-nação, verificase uma relativa sintonia das reformas, uma forte similitude entre alguns eixos estruturantes e estratégias adoptados, e até mesmo uma consonância argumentativa quanto aos imperativos das mudanças". 
Por um lado, isso tem levado alguns autores a afirmar que a globalização, por meio de um processo de regulação transnacional, tem gerado crescente integração ou interdependência econômica mundial. Gradualmente, em lugar das políticas específicas dos Estados-nação, ocorre uma "convergência de políticas" ou mesmo uma "convergência de paradigmas", ou seja, uma "invocação de políticas com base em princípios e tecnologias comuns, mecanismos operacionais idênticos e efeitos de primeira e segunda ordem semelhantes" (BALL, 2001, p. 112).

Nóvoa, ao analisar a educação em países da Comunidade ou União Europeia, aponta para essa convergência no campo das políticas educativas (normas e ações comuns) dos países $\operatorname{membros}^{13}$ :

[...] Os sistemas de educação europeus enfrentam hoje uma série de influências que levam à evolução similar, pelo menos em termos de suas configurações institucionais, de seus arranjos organizacionais e de suas estratégias de desenvolvimento. Isso não é incompatível com a preservação, dentro dos limites de cada Estado-Membro, de margens relativamente importantes de autonomia, muito mais evidente sobre a produção de um discurso de legitimação nacional na formulação de políticas alternativas. Eu também argumentei que a introdução no Tratado de Maastricht do conceito de cidadania européia tem consequências inevitáveis, a médio prazo, para a missão do sistema educativo e para a definição de algumas políticas "comuns" entre os diferentes Estados-Membros (NÓVOA, 1996, apud, AFONSO, 1998, p. 206).

Também Antunes (1999, p. 856), com base em documentos (resoluções, conclusões, decisões e diretivas) resultantes das reuniões do Conselho Europeu e dos Ministros da Educação, relaciona a produção de referências ideológicas e políticas, de modelos institucionais ou normas de ação no campo da educação, especialmente a partir de 1986, quando emergem os "programas de educação comunitária", orientados por objetivos comuns e tendo "impacto directo nos (e/ou envolvendo instituições ligadas aos) sistemas de ensino dos Estados-Membros da Comunidade Europeia" (ANTUNES, 1999, p. 858). Segundo a autora, é possível "apontar para o restabelecimento de uma agenda e políticas comunitárias para a educação, assentes em acções comunitárias e processos normativos (intensificados)" (ANTUNES, 1999, p. 860). Barroso (1999, p. 133) faz observações semelhantes:

[...] na maior parte dos países da União Européia, assiste-se igualmente a alterações no domínio da administração dos seus sistemas educativos que, no quadro mais vasto de processos de descentralização, se traduzem no aumento de competências e remodelação dos órgãos de gestão das escolas na elaboração de 'projectos educativos' e na instauração de mecanismos de avaliação e prestação de contas.

$\mathrm{Na}$ interpretação de Canário (2006), as reformas educativas decorrem do acelerado processo de integração econômica supranacional, fenômeno de âmbito mundial ligado à construção da União Europeia. Esse processo de "regulação transnacional" (BARROSO, 2005), "retirou dos Estados nacionais a capacidade de controlar os fluxos no interior e exterior das suas fronteiras reduzindo sua ação a um estatuto marginal" (CANÁRIO, 2006, p. 29). 
Em relação à América Latina, Rosar e Krawczyk (2001, p. 33-34) concluem que as circunstâncias não são distintas.

Nos últimos 10 anos, quase todos os países da América Latina iniciaram reformas educacionais, resultantes, em grande medida, de um processo de indução externa articulado com as políticas dos organismos internacionais de empréstimos para os países da região. A necessidade dessas reformas foi justificada mediante a publicação de pesquisas, que evidenciaram os logros e deficiências do sistema educativo à luz dos condicionantes da reestruturação do setor produtivo e das mudanças institucionais, que alteram a estrutura do Estado e das relações sociais no âmbito de uma nova ordem mundial. De fato, esses estudos vieram a ilustrar pontos de vista já assumidos pelos organismos internacionais e justificar um modelo pré-estabelecido de reforma educacional.

Para as autoras, "as reformas educativas em curso têm um caráter homogeneizador, tanto na leitura das realidades nacionais quanto nas suas propostas, impondo uma padronização de política educacional para a região" (ROSAR e KRAWCZYK, 2001, p. 40).

Em nossa pesquisa, "Política de Autonomia da Gestão Escolar: Uma análise comparada entre Brasil e Portugal", também concluímos que as reformas educativas empreendidas nos anos de 1990 nos dois países têm características similares. Observamos que ambas foram empreendidas segundo a inspiração gerencial e produtivista e que as políticas e práticas da educação foram submetidas aos imperativos da lógica de mercado e, ao mesmo tempo, às mudanças significativas no modo de regulação e atuação do Estado. Dentre suas características, observamos: descentralização da gestão; surgimento de novas estruturas de responsabilização e financiamento; aumento da flexibilidade institucional; favorecimento da participação social; encorajamento da competição; busca de parceria entre as diversas esferas de governo, do setor privado e da sociedade civil para financiar a educação pública, o que resulta no rompimento com a exclusividade do poder público; satisfação do cliente/consumidor; avaliações externas (CARVALHO, 2011).

Enfim, entendemos que os estudos comparados são fundamentais para enfrentar os desafios inerentes às mudanças sociais decorrentes da nova ordem globalizada, da reestruturação do setor produtivo e das mudanças institucionais na estrutura do Estado, especialmente tendo em vista que as novas problemáticas educativas não se restringem mais ao contexto nacional.

Desse modo, concordando com Almerindo Afonso (2000, p. 63), para quem as políticas educativas "só podem ser adequadamente compreendidas se forem referenciadas ao contexto mundial, ultrapassando assim algumas limitações inerentes às perspectivas tradicionais que circunscrevem a análise das reformas às fronteiras do Estado-nação", destacamos a relevância atual do estudo comparado.

Considerando que a comparação não é uma operação simples e implica o recurso a uma teoria da comparação, concordamos com Nóvoa (1998) quando defende a importância de uma estreita ligação entre as questões metodológicas e as discussões teóricas, bem como da identificação das bases ideológicas que subjazem às diferentes comunidades discursivas da educação comparada. Sem desconsiderar que comparar os sistemas educacionais implica adotar diferentes métodos, os quais expressam os antagonismos presentes nas relações sociais e as diferentes visões de mundo e de sociedade, optamos, em nossa pesquisa, pela perspectiva dialético-materialista. 
Dessa perspectiva, procuramos explorar a relação entre o contexto nacional e o internacional, comparando e analisando os distintos sistemas. Entendemos que a relevância do estudo comparativo consiste nas possibilidades que ele oferece para se apreender a relação dialética entre os níveis global e local, a articulação entre as particularidades e as tendências globais, e para distinguir da tendência universal o que é próprio/específico de um sistema. Em outros termos, por meio do método comparativo, podemos apreender o objeto de estudo em seu contexto, com base no que lhe é específico, mas sem tratá-lo como objeto isolado, separado daquilo que lhe dá significado, ou seja, da totalidade social da qual é parte, ou seja, abordá-lo como uma particularidade histórica. Enfim, concordamos com Franco (2000, p. 222), quando aponta para a necessidade de

[...] não perder a especificidade local do fenômeno e tratá-lo dentro das complexas relações sociais que o constituem enquanto preparação para o trabalho, em um mundo cultural e economicamente globalizado. $\mathrm{O}$ que significa compreendê-lo enquanto resposta estratégica aos problemas postos pela globalização econômica, pela reestruturação produtiva, pelos objetivos de qualidade e de competitividade, pelas transformações do mundo do trabalho e pelo desemprego estrutural.

Evidentemente, isso implica uma proposta metodológica que favoreça a elucidação dos mecanismos que engendram o próprio processo de globalização, que articulam ou dissolvem o local, o nacional e o global, a apreensão das interações dinâmicas, ou seja, do lugar que os fatores locais ocupam no movimento geral da sociedade e do que há de universal no particular. Em outros termos, implica "recuperar a totalidade social de que são portadores todos os fenômenos, embora, de um ponto de vista analítico, quase sempre os vejamos segmentados" (FRANCO, 2000, p. 224). Isto significa que o método não deve se limitar ao reconhecimento das semelhanças e diferenças existentes entre os fenômenos, mas explicar por que estes ocorrem ou porque o comportamento da parte é diverso do todo. Esse é um dos sentidos da comparação.

Outro aspecto importante é: comparar para quê?

Além de reconhecer as semelhanças e diferenças, justapor índices, correlacionar números, quantificar resultados obtidos com base em indicadores internacionais de desempenho e padronizar instrumentos comparativos, cujos parâmetros podem ser alheios ao nacional ou às condições de organização dos sistemas, a comparação implica interpretar os dados, questioná-los e analisar suas bases. Dessa maneira, é possível não só contribuir para um debate mais aprofundado, como também para valorizar o estudo comparado.

Além disso, mais do que destacar as singularidades de cada cultura e de cada individualidade, de distinguir o que lhe é próprio ou firmar sua diferença, é necessário reconhecer que a particularidade não se explica por si mesma. A comparação, nesse caso, deve ter a finalidade de descobrir o que existe de universal nos processos singulares, descobrir a relação recíproca entre o específico e o universal no mesmo fato. Em outros termos, a especificidade não pode ficar dissolvida no movimento mais geral da sociedade, mas também não pode ser tomada como se pudesse existir independentemente da totalidade a que pertence e que lhe dá sentido.

Para atingir esses objetivos da comparação, deve-se adotar uma metodologia que supere o particular (formas específicas e regionais), o imediato e o cotidiano e que tenha a preocupação de revelar a diversidade. Que sentido teria uma educação comparada que, ao 
procurar retratar uma situação, não tivesse a finalidade de encontrar soluções para os problemas, de orientar e fundamentar a tomada de decisões educativas? Como poderemos discernir com precisão se temos fragmentos como referência?

Outro aspecto importante a ser considerado é que, geralmente, comparamos os sistemas educativos. Por isso, devemos pensar na amplitude desse conceito, já que a educação não se limita à particularidade da prática educativa. Além disso, existem muitos aspectos implícitos na política educativa. Concordamos com Roger Dale (2004, p. 439), quando afirma que a educação

[...] centra-se em três questões fundamentais: a quem é ensinado o quê, como, por quem e em que circunstâncias?; como, por quem e através de que estruturas, instituições e processos são definidas estas coisas, como é que são governadas, organizadas e geridas?; quais são as consequências sociais e individuais destas estruturas e processos?

Estas questões centram-se nos princípios e processos da distribuição da educação formal, na definição, formulação, transmissão e avaliação do conhecimento escolar e em como é que estas coisas se relacionam entre si. Elas dirigem-nos no sentido de descobrir como é que aqueles processos são financiados, fornecidos e regulados e como é que este tipo de formas de governação se relacionam com concepções mais amplas de governação dentro de uma sociedade. Somos solicitados a perguntar como é que estas estruturas e processos, que tipicamente referimos sob a designação "sistemas educativos", afectam as oportunidades de vida dos indivíduos e grupos e a totalidade das relações dos sistemas educativos com as colectividades e instituições sociais mais amplas de que fazem parte.

Assim, um sistema é, fundamentalmente, um conjunto de realidades inter-relacionadas, mutuamente influenciadas. Conforme, Bonitatibus (1989, p. 23),

[...] é a negligência a este pressuposto básico da noção de sistema que frequentemente vicia os estudos comparativos, na medida em que tendem a simplesmente justapor elementos diversos, deixando de valorizar as relações, os fluxos e as trocas que se efetivam entre as partes. A justaposição sistemática fornece, dessa forma, apenas uma imagem rudimentar e simplista de uma realidade extremamente complexa, dinâmica e móvel.

\section{Considerações finais}

O estudo histórico da educação comparada permitiu verificar que, após um período de reconhecida importância, os estudos comparados sofreram um progressivo declínio, seja como campo de pesquisa seja como disciplina acadêmica nos cursos de formação de professores.

No entanto, entendemos que se trata de um relevante campo de estudo, um instrumento importante de conhecimento e de análise de nossa realidade educativa: "sempre que tomamos nossa própria cultura como único ponto de referência, tendemos a centrar nela todas as nossas reflexões, deixando de considerar aspectos e dimensões que apenas uma visão mais abrangente 
e diferenciada pode nos assegurar". O "conhecimento de si mesmo nascido do confronto com o outro" (BONITATIBUS, 1989, p. 14) alarga nosso campo de visão, transformando-se num instrumento bastante propício para o conhecimento mais fecundo de nossa própria realidade educacional.

Enfim, de nosso ponto de vista, a relevância da educação comparada decorre das possibilidades que ela oferece: 1) alargar nosso campo de visão quanto aos impactos da globalização sobre a reformulação dos sistemas educativos dos diferentes países; 2) identificar o que é comum ou idêntico e o que é específico nesses sistemas 3) verificar se existem alternativas para a uniformização ou padronização internacional das políticas públicas para a educação e mostrar quais são elas; 4) captar a relação entre os processos de globalização e regionalização como algo contraditório e mutuamente constituído; não linear.

No Brasil, a educação comparada poderia contribuir para os estudos das diferentes regiões ou diferentes estados (SAVIANI, 2001). Existe a necessidade de estudos que, no âmbito latino-americano, abordem as especificidades e semelhanças regionais, bem como suas intersecções com o processo mundial.

Em suma, levando em conta todos esses aspectos, é possível reconhecer a relevância da educação comparada na atualidade não apenas na pesquisa, mas também no ensino.

\section{Referências}

AFONSO, Almerindo Janela. Políticas Educativas e Avaliação Educacional. Para uma Análise Sociológica da Reforma Educativa em Portugal (1985-1995). Braga, Centro de Estudos em Educação e Psicologia, Instituto de Educação e Psicologia - IEP da Universidade do Minho, 1998.

Editora, 2000. Avaliação Educacional: Regulação e Emancipação. 2a ed., São Paulo: Cortez

ALTBACH, Phillip G. Tendencias en la Educación Comparada. Revista de Educación. Madrid, Espanha, nº 293, sept/dic, p. 295-309, 1990.

ANTUNES, Fátima. A Comunidade/União Europeia e transnacionalização da educação: elementos para debate. In: II CONGRESSO INTERNATIONAL DA AIPELF/AFIRSE. Education Et Politique. Lisboa, 1999. Actas..., Lisboa: AFIRSE Portuguesa (Association Francophone Internationale de Recherche em Sciences de L'Education)/Faculdade de Psicologia e Ciências da Educação da Universidade de Lisboa, 1999, vol. 2., p. 855-868.

BALL, Stephen J. Diretrizes Políticas Globais e Relações Políticas Locais em Educação. Currículo sem Fonteiras, vol.1, nº 2, p. 99-1116, jul/dez, 2001.

BARROSO, João. A Escola entre o Local e o Global. Perspectivas para o Século XXI. O caso de Portugal. In: BARROSO, João (Org.). A Escola entre o Local e o Global: Perspectivas para o Século XXI. Lisboa: EDUCA, Faculdade de Psicologia e de Educação da universidade de Lisboa, 1999, p. 129-142, (Colecção: Educa - Organizações). 
Regulação e desregulação nas políticas educativas: tendências emergentes em estudos de educação comparada. In: BARROSO, João (Org.). Escola Pública - Regulação, Desregulação e Privatização. Porto: Editora Asa, 2003, p. 19-48.

BARROSO, João; VISEU, Ana Sofia. A emergência de um mercado educativo no planeamento da rede escolar: de uma regulação pela oferta a uma regulação pela procura. Revista Educação \& Sociedade. Revista de Ciências da Educação/Centro de Estudos Educação e Sociedade, São Paulo: Cortez, Campinas, nº 84, vol. 24, p. 897-921, 2003.

BARROSO, João. Lês nouveaux modes de régulation dês politiques éducatives em Europe: de la régulation du système de régulations. In: Y. Duterq (Org.). Les régulations dês politiques d'éducation. Rnnes: Press Universitaires de Rennes, p. 151-171, 2005.

BEECH, Jason. Repensando la Transferencia Educativa: De la transferencia transnacional a los modelos universales de educácion. Disponível em www.fundacionluminis.org.ar/articulos. Acesso em setembro de 2007.

BERNESTEIN, Basil. Poder, Educación y Conciencia. Sociología de La Transmisión Cultural. Barcelona, EL Roure, 1990.

BONITATIBUS, Suely Grant. Educação Comparada. Conceito, Evolução e Método. São Paulo: EPU, 1989.

BURBULES, Nicolas C. e TORRES, Carlos Alberto. (ORGs.) Globalização e Educação:uma introdução. In: Globalização e Educação. Perspectivas críticas. Porto Alegre, Editora Almedina, 2004, p. 11-26.

CANÁRIO, Rui. A Escola e a Abordagem Comparada. Novas realidades e novos olhares. Sísifo. Revista de Ciência da Educação, n 1, set/dez, 2006, p. 27-36. Disponível em 2008, em http://sisifo.fnce.ul.pt. Acesso em março de 2008.

CARVALHO, Elma Júlia Gonçalves de. Gestão da Educação: em perspectiva comparada Brasil-Portugal. In: Anais do IV Congreso Nacional y III Encuentro Internacional de Estudios Comparados en Educación. Buenos Aires: SAECE - Sociedad Argentina de Estudios Comparados en Educación, Buenos Aires - Argentina, 2011.

CROSSLEY, Michael. Comparative and International Education: Contemporary Challenges, Reconceptualization and New Directions for the Field. Current Issues in Comparative Education, Teachers College, Columbia University, Vol. 4(2), 2002. Disponível em http://www.tc.columbia.edu/cice/Archives/4.2/42crossley.pdf. Consultada em abril de 2009.

DALE, Roger. Globalização e Educação: Demonstrando a existência de uma "cultura educacional mundial comum" ou localizando uma "agenda globalmente estruturada para a educação"? Revista Educação \& Sociedade, Revista de Ciências da Educação/Centro de Estudos Educação e Sociedade, São Paulo: Cortez, Campinas, vol 25, n 87, p. 423-460, maio/ago, 2004.

Globalización: ¿un nuevo mundo para la educación comparada? In: SCHRIEWER, Jürgen (Org.). Formación del discurso en la educación comparada. Ediciones Pomares, Barcelona, 2002, p. 69-90. 
FRANCO, Maria Ciavatta. Quando nós somos o outro: Questões teórico-metodológicas sobre os estudos comparados. Revista Educação \& Sociedade. Revista de Ciências da Educação/Centro de Estudos Educação e Sociedade, São Paulo: Cortez, Campinas, ano XXI, $\mathrm{n}^{\circ}$ 72, p.197-230, Ago/2000.

FURTER, Pierre. Os sistemas de formação em seus contextos. Introdução a um método de educação comparada. Rio de Janeiro, Editora FGV, 1982.

GOERGEN, Pedro L. Educação Comparada: uma disciplina atual ou obsoleta? Campinas, Revista Pro-Posições, Revista da Faculdade de Educação, vol. 2, n³ , dez, 1991, p. 6-19.

GONÇALVES e SILVA, Petronilha Beatriz. Educação comparada no contexto da globalização, considerando a diversidade. In: WERLE, Flávia O. Correa; CASTRO, Marta Luz Sisson. Educação Comparada na Perspectiva da Globalização e Autonomia. São Leopoldo, RS, Editora Unisinos, 2000, p. 23-39.

KELLY, Gail P.; ALTBACH, Phillip G. La Educación Comparada: Desafíos y Respuestas. In: KELLY, Gail P.; ALTBACH, Phillip G. (Org.). Nuevos Enfoques en Educación Comparada. Ed. Mandadori, Madrid, 1990, p. 353-374.

LAMARRA, Norberto Fernández; MOLLIS, Marcela e RUBIO, Sofía Dono. La Educación Comparada em América Latina: Situación y desafios para su consolidación acadêmica. Revista Española de Educación Comparada, n 11, p. 161-187, 2005. Disponível em: http://www.sc.ehu.es/sfwseec/reec11.htm. Acesso em abril de 2009.

LIMA, Licínio C. e AFONSO, Almerindo Janela. Reformas da Educação Pública. Democratização, Modernização, Neoliberalismo. Porto: Edições Afrontamento, 2002, (Coleção Biblioteca das Ciências do Homem).

LOURENÇO FILHO, Manoel B. Educação Comparada. 3ª ed, Brasília, INEP/MEC, 2004.

MADEIRA, Ana Isabel. Perspectivas Actuais da Investigação em Educação Comparada: Um Olhar Luso-Brasileiro. Conferência de Abertura do $4^{\circ}$ Encontro Internacional da Sociedade Brasileira de Educação Comparada PUCRS - Porto Alegre, 1 a 3 de Abril de 2008. Disponível em http://www.sbec.org.br/evt2008/trab04.pdf. Acesso em abril de 2009.

MALET, Régis. Do Estado-Nação ao Espaço-Mundo: As Condições Históricas da Renovação da Educação Comparada. Revista Educação \& Sociedade, Revista de Ciências da Educação/Centro de Estudos Educação e Sociedade, São Paulo: Cortez, Campinas, vol. 25, ${ }^{\circ}$ 89, p. 1301-1332, set/dez, 2004.

MARTINI, Jussara Gue. Educação Comparada: Construindo Caminhos. Coletânea do PPGEDU, Porto Alegre, vol. 3, nº 7, p. 332-29, jul/ago, 1996.

MARQUEZ, Angel Diego. Educación Comparada. Teoria e Metodologia. Buenos Aires, Livraria El Ateneo Editorial, 1972.

MEYER, John. W.; RAMíREZ, Francisco O. La insitucionalización mundial de la educación. In: SCHRIEWER, Jürgen (Org.). Formación del discurso en la educación comparada. Ediciones Pomares, Barcelona, 2002, p. 69-90.

MOLLIS, Marcela. La educación comparada de los 80: Memoria y Balance. Revista de Educación, Madrid, Espanha, no 293, p. 311-325, set/dez, 1990. 
NOGUEIRA, Sônia M. de Almeida. Educação Comparada e o Pensamento Educacional Criador - o essencial de uma relação fertilizada. Brasília, Revista Em Aberto, nº 64, p. 35-43, out/dez, 1994.

NÓVOA, Antonio S. Sampaio. História da Educação. Provas de Agregação Não Publicadas. Lisboa, Universidade de Lisboa, Faculdade de Psicologia e Ciências da Educação, 1994. . Histoire \& Comparaison (Essais sur l'Éducation). Lisboa: Educa, 1998.

ROSAR, Maria de Fátima F. e KRAWCZYK, Nora Rut. Diferenças e Homogeneidade: Elementos para o Estudo da Política Educacional em Alguns Países da América Latina. Revista Educação \& Sociedade, Revista de Ciências da Educação/Centro de Estudos Educação e Sociedade, São Paulo: Cortez, Campinas, ano XXII, n 75, p. 33-47, ago/2001.

SAVIANI, Demerval. História Comparada da Educação. História da Educação. ASPHE/FaE/UFPel, Pelotas: Editora da UFPel, n¹0, out. 2001, p. 5-16.

SCHRIEWER, Jürgen. Sistema Mundial e Inter-relacionamento de Redes: a Internacionalização da Educação e o Papel da Pesquisa Comparativa. Brasília, Revista Brasileira de Estudos Pedagógicos, vol. 76, n 182/183, p. 241-302, jan/ago, 1995.

VELLOSO, Agustín e PEDRÓ, Francesc. Manual de Educácion Comparada. Vol. II Teorias, Investigaciones, Perspectivas. Barcelona, PPU, 1993.

WALLERSTEIN, I. et al.. Para abrir as Ciências Sociais - Relatório da Comissão Gulbenkian sobre a reestruturação das Ciências Sociais. Lisboa: Europa-América, 1996.

WERLE, Flávia O. Correa; CASTRO, Marta Luz Sisson. Administração Comparada: uma análise das publicações na América Latina. In: WERLE, Flávia O. Correa; CASTRO, Marta Luz Sisson. Educação Comparada na Perspectiva da Globalização e Autonomia. São Leopoldo, RS, Editora Unisinos, 2000, p. 93-108.

WILSON, David N. The future of comparative and international education in a globalised word. International Review of Education - Internationale Zeitschrift für Erziehungswissenschaft, Revue Internationale de l'Education (1-2), p. 15-33, 2003. Disponível em http://unjobs.org/tags/comparative-education. Acesso em maio de 2009.

\section{Notas}

1 Uma versão preliminar desse texto foi apresentada oralmente no "Tercer Congreso Nacional/ Segundo Encuentro Internacional de Estudios Comparados en Educación. Reformas Educativas Contemporáneas: ¿Continuidad o Cambio?" SAECE - Soceidad Argentina de Estudios Comparados en Educación, Buenos Aires, 2009.

${ }^{2}$ Universidade Estadual de Maringá (UEM)

${ }^{3}$ De acordo com Bonitatibus (1989, p. 41), “enquanto os estudos do início do século são, especialmente, a respeito do ensino popular, elementar, obrigatório e gratuito, pelo fim do século já se manifesta o interesse pelo ensino profissional (técnico e comercial), assim como pelos níveis secundários e superiores de ensino".

${ }^{4}$ Wallerstein et al. (1996, p. 118) sublinham: “[...] os Estados eram a unidade de comparação, ora de estudos de 'política externa', cujo objeto consistia no estudo das políticas dos estados uns para com os outros, e não no estudo das características emergentes das estruturas transestatais".

${ }^{5}$ Conforme Márquez (1972, p. 32), "Em todo o percurso de nossa disciplina se encontram ideias similares quanto aos benefícios que no campo da educação proporcionam os estudos comparados: permitem um maior 
conhecimento e uma maior compreensão dos sistemas nacionais e dos fatores que os condicionam; possibilitam detectar falhas mais notórias dos sistemas e oferecem informações acerca das soluções adotadas em outros países para sanar falhas iguais ou similares; contribuem para a reforma da educação e constante aperfeiçoamento desta; favorecem um entendimento mais amplo entre os povos e, portanto, facilitam a compreensão e colaboração internacional e contribuem para a realização da paz".

${ }^{6}$ Em estudo recente sobre a educação comparada na América Latina, Lamarra; Mollis e Rubio (2005, p. 166) informam que no Brasil a investigação da educação comparada tem se desenvolvido em cursos de pós-graduação de diversas universidades brasileiras. Porém, seu desenvolvimento na graduação é muito limitado. Segundo os autores: "Com exceção da Universidade Federal do Paraná, nenhuma outra universidade federal inclui a matéria comparativa nos currículos dos cursos de graduação. Tão pouco o faz uma das universidades privadas mais antigas e de maior prestígio no estado como a Universidade Católica. Por sua vez, nem a reconhecida Universidade de Campinas que funciona no Estado de São Paulo (UNICAMP) ensina Educação Comparada em qualquer um dos cursos de graduação na área da Educação".

${ }^{7}$ Conforme Nogueira (1994, p. 35), "a Sociedade Brasileira de Educação Comparada, fundada em 1983, o Grupo de Estudos e Pesquisas sobre Educação na América Latina e Caribe, da Faculdade de Educação da UNICAMP e FLACSO caracterizam ações nesse sentido".

${ }^{8}$ Crossley (2002) considera que poucos estudos têm dado atenção a estas diferenças. Por isso, defende que este deve ser um campo a ser explorado pelos estudos comparativos em educação.

${ }^{9} \mathrm{O}$ autor entende ser necessário prestar atenção aos efeitos locais da globalização. Nesse sentido, aponta para a importância de investigações mais sensíveis às diferenças culturais (com base na etnografia e na interpretação/hermenêutica), aos paradigmas que enfatizam micro estudos de educação e ao contexto, especialmente o pós-colonial.

${ }^{10}$ Velloso e Pedró (1993, p. 371) apontam para a falta de interesse, tanto por parte dos pesquisadores como dos programas de formação docente, por estudos comparativos no campo da Administração da Educação nos últimos cinqüenta anos, de forma que este vem sendo considerado um campo emergente de investigação.

${ }^{11}$ No campo educacional, a agenda geralmente privilegia certas políticas de avaliação, financiamento, padrões de formação de professor, currículo e procedimentos de avaliação de desempenhos e prestação de contas que aproximam as organizações escolares da lógica do mercado. Ou seja, sugerem medidas que enfatizam a redução do patrocínio e financiamento estatal, passando a conceder subsídios e a estabelecer parcerias; a introdução de mecanismos de mercado para regular as trocas educativas, e impõem modelos de eficiência e eficácia emprestados do setor empresarial (BURBULES e TORRES, 2004).

${ }^{12}$ Esses efeitos são apontados por Wilson (2003), ao analisar os impactos da globalização e comunicação (TIC) (manuais, revistas acadêmicas, conferências, as agências internacionais, sociedades profissionais, a Internet impressos on-line, intercâmbios por e-mail, educação a distância) na ampliação e propagação dos estudos comparativos internacionais.

${ }^{13}$ De fato, não existem condicionantes jurídico-formais para as políticas educativas no caso da adesão à CEE ou um referencial obrigatório para a ação comunitária em matéria de educação, de forma a homogeneizá-la ou uniformizá-la. Em 1992, no "Tratado da União Européia", Capítulo III, referente à educação, à formação profissional e à juventude", encontra-se a afirmação de que "a comunidade contribuirá para o desenvolvimento de uma educação de qualidade, incentivando a cooperação entre Estados membros e, se necessário, apoiando e completando a sua acção, respeitando integralmente a responsabilidade dos Estados membros pelo conteúdo do ensino e pela organização do sistema educativo, bem como a sua diversidade cultural e lingüística". Ao se fazer essa afirmação, ao mesmo tempo, se está admitindo a diversidade de políticas em relação aos sistemas de educação. Apesar disso tudo, de acordo com Afonso (1998, p. 206), “[...] não se deve excluir a possibilidade de haver um impacto importante de outros factores no sentido de uma convergência de políticas, ainda que não consignadas do ponto de vista jurídico-formal [...] mesmo que não tenham carácter impositivo, acabam por ter repercussões directas ou indirectas nos Estados-membros".

Recebido em dezembro-2012

Aprovado em abril-2013 